The Research Journal of the Costume Culture

[Original Article]

Received December 12, 2016

Accepted February 21, 2017

${ }^{\dagger}$ Corresponding author

(hjmap@hanmail.net)

ORCID

MINA PARK

http://orcid.org/0000-0003-4988-4743

Hyunzin Ko

http://orcid.org/0000-0001-8763-3422

This paper is a part of a doctoral dissertation.

\section{(A) study on digital fashion from the aesthetic perspective of media}

\author{
Mina Park ${ }^{\dagger}$ and Hyun Zin Ko \\ Dept. of Apparel Design, Konkuk University, Korea \\ 디지털 패션의 매체 미학적 관점에 관한 연구 \\ 박 민 아 $^{\dagger}$ 고 현 진 \\ 건국대학교 의상디자인과
}

\begin{abstract}
When digital media and images are combined, their significant sociocultural impacts can be exercised. Therefore, this study analyzes digital images shown in such trends of digital media compared to the digital fashion from an aesthetic perspective. Research and empirical studies are focused upon to analyze the aesthetic characteristics of digital fashion. Digital Fashion comprehensively refers to fashion design using computers and software, and is considered as "Fashion Design utilizing Digital Technologies" including computer software and hardware perspectives, so that it may be renamed "Digital Fashion." The esthetic characteristics shown in the Digital Fashion defined above are analyzed according to how media philosophers conceptualize the digital image. First, from the perspective of creation, Digital Fashion Images are technical images produced by computers. Uncanny characteristics expressed through virtual images look more realistic than the actual ones used in experimental works of fashion designers. Such virtuality dynamically expresses various colors and fabric patterns through lights using digital technologies that do not yet exist in cloth form, rather in a non-material form of dynamic virtual imagery. Digital fashion images on monitors express digital fashion designs by shaping virtual images through 3D printing. Second, Digital Fashion Images from the perspective of acceptance are created through deconstruction, while fashion has only been previous viewed visually, Digital Fashion delivers immersions of visual touches as if directly experienced for accepters. Digital Fashion will continuously develop and become more influential as it converges with digital media.
\end{abstract}

Keywords: digital fashion(디지털 패션), digital image(디지털 이미지), thinking of media aesthetic(매체 미학적 사유), the perspective of creation(생성의 관점), the perspective of acceptance(수용의 관점)

\section{Introduction}

21세기 디지털 기술의 도입은 현대사회에 혁명이라 불릴 정도로 많은 변화를 가 져왔다. 디지털 매체를 통해 이미지를 활용한 커뮤니케이션 방법의 변화와 디지털 
기술을 접목한 디자인, 문화, 예술의 협업이 등장하 여, 다양한 영역에서 디지털 컨버전스(digital convertgence)가 나타나고 있다. 패션분야에서도 이러한 디 지털 기술이 융합된 패션디자인이 지속적으로 개발 되어, 웨어러블 디바이스(wearable device)가 활용된 스마트 웨어(smart wear)가 등장하고 있다. 특히 2013 년도부터 $3 \mathrm{D}$ 디지털 프린팅으로 인해 다양하고 새로 운 조형의 패션디자인이 시도되고 있고, 디지털 기술 이 활용된 가상현실(Virtual Reality: VR) 및 증강현실 (Augmented Reality: AR)이 나타난 3D 가상 디지털 패션쇼가 열리고 있다. 그리고 패션의 표면(surface) 에 나타난 컬러와 그래픽 무늬의 표현 방법에서도 디 지털 기술의 융합을 통해 이전에는 볼 수 없었던 다 양한 변화가 나타나고 있다.

한편, 텍스트 중심에서 이미지 중심으로의 패러다 임의 전환에 따라 디지털 시대에 맞게 디지털 이미지 의 매체적 특성에 관한 학문적 연구들이 매체 미학 분야에서 활발하게 진행되고 있다. 그럼에도 불구하 고 현재 패션분야에서는 매체 미학적 관점으로 디지 털 패션 이미지에 관한 학문적 연구는 부족한 실정이 다. 디지털 기술이 본격적으로 활발하게 나타난 1990 년도 말부터 현재까지 선행되어지고 있는 디지털 패 션에 관련된 연구는 디지털 시대 문화 현상, 패러다 임의 변화와 패션을 연결 지어 연구한 논문(Chun, 2010; Kim, 2005; Kim, 2010; Lee, 2003), 디지털 패션디자 인의 조형적 특성에 집중한 연구(Chun, 2008; Chun \& Ha, 2006; Jang \& Hyun, 2003; Kim, 2003), 웨어 러블 컴퓨터, 스마트 웨어에 대한 연구와 같이 디지 털 의상의 인텔리전트 기능과 기술에 중점을 둔 연구 (Heo \& Lee, 2013; Hyun, 2002; Kim, 2007; Kwak, 2009; Park \& Lee, 2001) 등으로 나타났다. 이렇게 디 지털 패션에 관한 연구가 진행되고 있음에도 불구하 고, 선행 연구들은 디지털 시대의 패션에 나타난 조 형적 분석 측면이나 디지털의 도구적 특성을 활용한 방법적인 측면에서만 연구되고 있었다. 또한 그 정의 에 관해서도 혼용되어, 명확하게 규정되지 않아 이에 대해 보다 정리된 관점이 필요한 시점이다.

따라서 디지털 패션은 디자인 이미지와 발전하고 있는 디지털 매체의 양면적 가치가 혼재되어 있는 패 션 분야에서 더욱이 주목할 만하며, 디지털 패션에 대한 명확한 정의와 이에 관한 연구도 다각적으로 이
루어져야 한다. 이에 본 연구에서는 디지털 패션에 나타난 조형적인 고찰에 국한된 단편적인 분석이나 또는 도구적 특성을 활용한 방법적 관점에서 고찰하 기 보다는 기존의 연구에서 다루어지지 않았던 미학 적 관점에서 논의하고자 한다. 본 연구는 디지털 패 션에 대해 명확하게 정의를 내리는 연구와 디자인 이 미지에 의한 미적 표현이 중요한 패션에 있어서도 이 와 같은 매체 미학적 관점에서의 논의가 필요하다고 사료되어, 매체 미학적 관점에서 디지털 패션을 분석 해 보았다.

본 연구의 연구 문제는 다음과 같다. 첫째, 디지털 이미지에 관한 일반적 정의 및 특성과 디지털 이미지 에 대한 디지털 매체 미학자들의 사유를 분석한다. 둘째, 선행연구를 바탕으로 디지털 패션의 개념을 명 확히 규명하고, 이를 바탕으로 디지털 패션디자인 사 례 유형을 분석한다. 셋째, 디지털 이미지에 대한 디 지털 매체 미학자들의 관점을 통해 앞서 고찰한 현대 디지털 패션의 미학적 특성을 밝힌다.

본 연구 방법은 문헌적 연구와 실증적 연구, 사례 조사를 병행하였다. 먼저 디지털 이미지의 일반적 정 의와 디지털 매체 미학자들의 사유를 통해 디지털 이 미지를 분석하기 위해 디지털 이미지와 디지털 매체 미학 관련 전문 서적, 선행 연구, 학술 논문, 웹 사이 트 백과사전 등을 중심으로 분석하였다. 디지털 패션 의 명확한 개념 정의를 위해 디지털 패션 관련 선행 연구들을 중심으로 디지털 패션에 대한 정의와 유형 을 정리하였으며, 각 유형에 따른 사례들을 분석하기 위해 문헌적 연구와 실증적 연구를 병행하였다. 디지 털 매체 미학자의 관점에서 연구된 디지털 이미지에 대한 디지털 매체 미학적 사유 분석틀에 따라 디지털 패션 사례를 매체 미학적 관점에서 분석하였다. 이를 위해 사용된 디지털 패션과 디자인 사례 자료는 디지 털 패션 관련 전문 서적과 선행 연구, 패션 전문 사이 트, 인터넷 칼럼 및 뉴스 기사를 활용하였다. 또한 디 지털 패션의 대표적인 디자이너와 브랜드의 공식 홈 페이지와 디자이너와 협업을 한 아티스트의 공식 홈 페이지를 포함하여, 그 외에 디지털 패션을 보여주고 있는 인터넷 자료를 검색하여 활용하였으며, 일부는 동영상 자료를 직접 캡처하거나 촬영하였다.

본 연구에서 다룬 디지털 패션은 착용이 가능한 일 상생활의 웨어러블 컴퓨터 의상뿐 아니라, 연구 개발 
되고 있는 의상, 패션 컬렉션 의상, 퍼포먼스를 위한 의상, 광고 의상 등을 포함하고 있으며, 디지털 이미 지 특성이 나타난 패션 컬렉션 무대와 퍼포먼스를 구 현하는 공간도 포함하고 있다. 디지털 패션디자인으 로 선정된 사례는 디지털 기술의 전문적인 특성 상 패션 디자이너와 전문 아티스트와 타 분야 전문가와 의 협업을 통한 디지털 패션디자인도 포함하였다. 연 구의 범위는 디지털 기술과 패션이 활발하게 나타나 기 시작한 1990년대부터 현재까지로 한정하였다.

\section{Theoretical Background}

디지털 매체가 중요하게 나타나고 있는 21세기 현 대에는 디지털 매체에 의해 생성된 디지털 이미지를 누구나 쉽게 접할 수 있을 뿐만 아니라, 디지털 이미지 를 생성하는 생산자이자 동시에 수용하고 있는 사용 자가 되었다. 따라서 이러한 디지털 매체를 논의할 때 '디지털 이미지'에 관한 연구들이 많이 진행 중이 다. 이에 본 연구는 이러한 디지털 매체의 경향에서 나타난 디지털 이미지의 정의와 이에 대한 미학적 관 점을 고찰해 보았다. 그리고 디지털 패션디자인 사례 분석을 위해 디지털 패션에 대한 명확한 정의와 특성 을 연구하였다.

\section{The definition of digital image}

디지털(digital)이라는 단어의 디지트(digit)는 사람 의 손가락이라는 의미에서 유래한 말로서("Digital", n.d.), 0 과 1 의 반복적 조합을 통해 모드 정보인 숫자 와 문자는 물론 소리와 영상까지를 표현할 수 있는 것으로(Kwon, 2008) 분절적인 비연속적 이진법 논리 를 사용한다. 디지털 이미지(digital image)의 사전적 정의는 데이터를 문자나 수치 형식으로 표시하기 위 한 이산적인 신호로 만든 그림이나 사진으로(“Digital Image", n.d.) 디지털화(digitizing)된 이미지를 뜻한 다. 디지털 이미지는 컴퓨터를 통해 만들어낸 상상적 인 이미지로 수식연산에 의한 시각화라고 할 수 있다 (Lee, 2004). 최초의 디지털 이미지는 1950년대 중반 미국 국립표준연구소에서 러셀 커쉬(Russel Kirsh)와 과학자 동료들이 사진 표면의 강도 변화를 기록하는 $\mathrm{NBS}$ 기계적 드럼 스캐너를 개발한 후 $\mathrm{ESAC}$ 컴퓨터 로 라인 드로잉을 추출하고, 물체의 수와 문자를 인
식하여 오실로스코프(oscilloscope)로 나타내도록 프 로그램 하였다(Mitchell, 1992/2005).

디지털 이미지는 아날로그 이미지를 디지털화하여 생성하거나, 또는 0 과 1 의 조합을 통해 비트의 비연속 적인 이진법 논리를 사용한 픽셀 이미지이다. 디지털 매체에 의해 생성된 기술적 이미지로서, 현실적 공간 과 시간을 벗어난 0 차원의 시공간으로 구성되었으며, 비물질적 가상공간의 이미지이다. 가상공간에서의 시 각적 이미지들은 디지트의 형태로 존재하며, 네트워크 에 의해 연결된 가상공간에서 그 모습을 나타낸다. 이 렇게 형성된 디지털 이미지는 실재세계의 변화와 더불 어, 현실보다 더 현실 같은 가상현실의 이미지를 형성 한다. 이 가상현실은 기본적으로 시각적인 이미지를 형성하지만, 그 수용 과정에서 시각과 함께 모든 지각 에 복합적으로 영향을 미치고 있다. 디지털 매체는 시 각과 청각 그리고 촉각을 구현하여, 다양한 지각 체험 이 가능한 복합 매체이듯이, 디지털 이미지도 복합 지 각적으로 작용하고 있다(Park, 2016).

디지털 매체에 의해 생성된 가상 이미지는 인간의 사유방식, 존재방식, 지각방식을 변화시키고 있다. 과 거의 예술에서 나타난 가상 이미지는 예술가의 구상 을 미적으로 구체화하고 형상화해내는 것을 의미하 였으나(Jung, 2012), 디지털 매체에서의 가상 이미지 는 그러한 의미와 함께 현실에 존재하지 않는 새로운 형태의 이미지를 포함하는 개념이다. 최근에는 가상 현실의 한 분야로 가상 이미지를 합성하여, 현실에 존 재하는 사물처럼 보이도록 하는 컴퓨터 그래픽 기법 으로 증강현실까지(Park \& Ko, 2014) 나타나 다양한 분야에서 활용하고 있다. 이러한 문화 예술적 현상에 서 더 나아가 디지털 이미지는 원본과 복제, 본질과 가상 그리고 기록과 허구 사이를 구분 짓는 본질적인 차이를 없애고 이들의 존재론적 변화를 가져왔다.

\section{Aesthetic perspective of the digital image}

디지털 이미지는 매체 철학자들의 사유를 통해 미 학적 관점으로 연구되어지고 있다. 디지털 매체는 우 리의 존재와 사유방식을 획기적으로 바꾸어 놓았고, 디지털 매체 철학자들은 바로 이러한 변화에 주목하 고 있다. 디지털 매체에 의해 생성된 이미지는 매체 미학에서 실재(實在: reality)와 가상(假想: virtual)에 관 한 새로운 존재론적 관점으로 설명되어질 수 있다. 디 
지털 이미지는 실재 존재하는 이미지를 재현하여 생성 하기도 하고, 실재 존재하지 않는 가상 이미지를 존재 하는 것처럼 생성하기도 한다. 또, 실재보다 더 실재 와 같은 가상 디지털 이미지는 시각적 매체임에도 불 구하고, 수용자가 마치 직접 접촉하고 있는 것과 같 은 체험을 가능하게 만들고 있다. 이처럼 디지털 매체 의 등장은 디지털 이미지를 생성하는 방식과 수용하 는 방식에 혁신적 변화를 가져왔기 때문에 매체 미학 에서 이 부분에 집중적으로 논의하고 있는 것이다. 또한 기존의 아날로그 이미지와 달리 디지털 이미지 는 원본성을 갖지 않으며, 완성된 결과물뿐 아니라, 생성되는 과정이 중요하다. 디지털 매체에 의해 생성 되는 과정들이 또 다른 결과물이 될 수 있기 때문이 다. 그리고 디지털 이미지가 생성이 되면 수용하는 입장에서 상호작용을 이루기 때문에, 매체에 의해 기 술 재생산 가능성을 전제로 해서 생겨난 기술적 이미 지인 디지털 이미지는 생성과 수용의 관점에서 사유 를 정리할 필요가 있다. 디지털 매체에 의해 생성되 고 수용하고 있는 디지털 이미지는 현재까지 매체 철 학자들에 의해 많은 철학적, 미학적 논의가 활발하게 이어지고 있다. 이에 디지털 매체 미학의 대표적인 철학자로 발터 벤야민(Walter Benjamin), 장 보드리 야르(Jean Baudrillard), 빌렘 플루서(Vilem Flusser)를 중심으로 질 들뢰즈(Gilles Deleuze), 마셜 맥루언 (Marshall McLuhan), 권터 안더스(Gunter Andrs), 폴 비릴리오(Paul Virilio) 등의 철학자들의 디지털 매체 미학적 사유를 분석하였다.

매체 철학에서 디지털 이미지를 분석하기 위해서 는 사진이라는 매체로부터 분석이 시작되는데, 이는 매개물을 이용하여 만들어진 최초의 기술적 이미지 가 사진이기 때문이다. 매체와 예술적 상황을 연결해 서 새로운 예술 형태인 디지털 이미지는 컴퓨터를 활 용하여 디지털 매체가 만들어낸 대표적인 기술적 이 미지이다. 벤야민에 의하면 기술적 이미지인 사진은 전통적인 예술 이미지와 다르게 기술 재생산 시대의 특징인 아우라(aura)의 몰락으로 인해 원본성이 없으 며, 일시성, 반복성이 긴밀하게 연결되어 있다(Sim, 2012). 전통적인 예술에서 생성된 이미지는 현존하는 것의 재현을 의미하였으나, '시뮬라시옹(simulation)' 이론의 철학자인 보드리야르는 매체 예술에서 생성 된 이미지를 모방으로서의 미메시스(mimesis)가 아닌
실제로 존재하지 않는 대상을 존재하는 것처럼 만들 어 놓은 시뮬라크르(simulacra)를 의미한다고 했다(Jin, 2014). 시뮬라크르는 디지털 매체 시대의 특징이 되 었으며, 디지털 이미지는 기존에 있었던 실재의 재현 형태가 아닌 가상적인 이미지를 시뮬라크르로 비물 질적인 형태를 가지고 있다. 그러나 플루서는 디지털 이미지가 이미 존재하는 것을 재현하는 것이기도 하 며, 존재하지 않는 피사체를 인공적으로 생성하는 가 상적인 새로운 존재라고 했다. 이러한 이미지를 생산 하고, 수용하는 작용과 더불어 인간의 본성 자체에도 변화가 일어나고 있음을 보았다(Flusser, 1994/1999). 존재론적으로 보았을 때, 이제 디지털 이미지는 존재 하는 사물의 현상과 가상이 아니라, 본질이 되었다고 볼 수 있다. 따라서 디지털 매체 시대에 디지털 이미 지는 실재와 가상을 구분하는 것은 의미가 없으며, 실 재보다 더 실재 같은 하이퍼 리얼리티(hyper reality) 이미지가 될 수 있다. 또한 시뮬라시옹을 통해 이미 지와 원본성의 문제를 실재와 가상을 둘러싼 철학적 논점으로 생성과 수용의 관점에서 볼 수 있다.

이렇게 디지털 매체에 의해 생성된 디지털 이미지 는 수용자에게 시각적 촉각성을 통해 새롭게 지각되 므로, 사물의 현상과 형태의 지각 방식을 매체 미학 의 사유를 통해 수용자 관점에서 연결시켜 볼 수 있 다. 벤야민은 기술 재생산 시대의 새로운 예술의 등 장과 지각의 구조 변화 간의 관계에서 새로운 지각방 식을 언급하면서, ‘촉각적질'을 주목했다(Sim, 2012). 예술의 수용에 관한 이론에서 시각적, 촉각적 지각은 중요한 지각 형태이다(Sim,2012). 어떤 사물의 현상 과 형태를 시각적으로 지각하지만, 촉각성과 유사한 지각의 체험을 준다. 들뢰즈의 '눈으로 만진다'는 관 념은 ‘형태의 변형'이 아니라, '만지는 눈, 눈의 만지 는 시각’을 획득하기 위한 활동이라고 하였고, 시각 적 촉각성은 디지털 매체에 적합한 방식으로 보았다. 또한 맥루언은 촉각이란 단순한 피부접촉이 아니라, 정신 속에서의 사물의 생명 그 자체라고 말하면서, 감각을 각각의 다른 감각으로 전화시켜 의식을 부여 해 주는 힘으로, 즉 '공통감각(common sense)'이라고 칭하였다(McLuhan, 1994/2002). 이는 수용자가 직접 신체에 접촉되지 않아도, 디지털 이미지를 시각적 지 각만으로 촉각성과 유사한 지각의 체험을 의미한다 (Sim, 2012). 또한 가상의 디지털 이미지 공간에서 시 
각적 촉각성을 통해 디지털 이미지에 몰입되어, 실제 와 같은 경험에 대해 수용자의 반응을 유도한다. 따 라서 가상의 이미지 공간에서는 몰입기술을 통해 현 실의 주체가 가상현실 공간에 입장하여, 가상의 환경 이 주체의 움직임에 따라 실시간으로 이미지를 바뀌 어 상호작용하게 된다. 이러한 의미에서 디지털 이미 지는 인간과 상호작용하는 이미지로 볼 수 있다. 그 리고 더 나아가 가상 이미지가 현실 세계로 튀어나오 는 증강현실에서는 디지털 기술에 의해 생성된 이미 지 공간 안에서 수용자는 가상과 현실이 중첩된 파타 피직스(pataphysics)를 경험하게 된다. 여기서 파타피 직스는 가상과 실재, 허구와 사실이 중첩되는 것을 의미한다(Chin, 2014a). 수용자 입장에서는 이미지와 거리를 두고 시각적으로 보기보다는 디지털 이미지 안으로 들어가 몰입을 체험하고, 디지털 이미지를 수 용하는 과정에서 시공간의 제한이 없는 유비쿼터스 공간을 누릴 수 있다. 이렇게 생성된 디지털 매체 시 대의 가상현실 이미지 공간은 시뮬레이션된 공간이 고, 기존의 실제 공간 자체가 디지털화되어 물질에서 비물질로 변화되고, 가상 이미지 공간에 존재하는 것 들 또한 비물질로 변형되는 존재론적 혁명이 일어나 는 것이다(Park, 2016). 이처럼 디지털 이미지는 생성 과정에서 편집 기술에 의해 시공간을 해체하거나 재 구성할 수 있게 만들었으며, 이를 통해 다른 시공간 에 대한 체험을 제공하므로, 색다른 미학적 경험을 가능하게 한다. 이러한 상황 속에서 디지털 작품을 분석하는 것만이 아니라, 수용자의 지각방식과 체험 이 중요하며, 매체 미학의 중심축은 수용자가 된다. 수용자 측면에서 디지털 이미지를 통해 원하는 시간 과 장소에 예술작품을 언제든지 볼 수 있는 기회를 가지게 되었다. 디지털 매체는 정보전달 방식만 바꾸 어 버린 것이 아니라, 이를 수용하는 방식이 필연적 으로 인간의 사유와 존재 방식 그리고 예술의 방식에 도 영향을 미쳤다.

따라서 매개물인 컴퓨터가 개입되어 생성된 디 지털 이미지는 매체 미학의 존재론적 관점에서 실재 와 가상에 관한 새로운 존재와 사유방식에 변화를 가 져왔다. 생성의 관점을 통해 본 디지털 이미지는 디 지털 매체에 의해 복제와 반복이 손쉬워지면서, 원본 성이 의미가 없어졌으며, 비물질적인 가상 이미지를 생성한다. 수용의 관점을 통해 본 디지털 이미지는
비물질적인 가상 이미지를 수용자 입장에서 몰입하 여 시각적 촉각성을 체험하고, 시공간 해체에 의해 새롭게 지각되며, 증강현실에서 상호작용하고 있다. 디지털 이미지는 생성과 수용의 관점에서 분산적 지 각을 통해 디지털 도구로 편집이 가능하며, 디지털 이미지가 생성되어가는 과정이 또 다른 결과물로 나 타나기 때문에 생성된 이후에도 수용자의 상호작용 에 따라 전혀 다른 결과물이 나올 수 있다.

\section{The definition of digital fashion}

디지털이 발전된 현재에도 디지털 패션의 개념이 아직까지 명확하게 정의되고 있지 않다. 현재 디지털 시대에 나타난 디지털 문화와 사이버적이고 미래적 인 이미지를 표현한 '디지털 시대의 패션(digital age fashion)'과 디지털 도구를 활용하여 표현한‘디지털 패션(digital fashion)'이 혼용되어 사용되고 있다. 흔 히 웨어러블 컴퓨터(wearable computer), 스마트 웨어 (smart wear), 유비쿼터스 패션(ubiquitous fashion) 등 과 같은 디지털 디바이스와 기술이 활용된 여러 용어 들이 함께 쓰이고 있다. 이는 패션에 있어 디지털 기 술과의 융합이 빠르게 계속적으로 발전되고 있음을 보여줌과 동시에, 과부하된 정보들에 의해 디지털 패 션 용어 정의가 필요한 상황을 반영하고 있다. 선행 연구를 통해 개념과 역사적인 흐름에 따라 디지털 패 션을 표현하고 있는 용어를 살펴보면, 스페이스 룩 (space Look), 테크노-사이버 패션(techno-cyber fashion), 사이버 펑크 패션(cyber funk fashion), 미래주의적 패 션(futuristic fashion), 미래주의(futurism, 퓨처리즘) 등과 같이 디지털 시대의 패션을 이미지로 표현하고 있는 용어들과 하이-테크 패션(high-tech fashion), 인 텔리전트 의복(intelligent garment), 라이트 그래피티 패션(light graffiti fashion), 테크놀로지 패션(technology fashion), 스마트 웨어, 웨어러블 컴퓨터, 유비퀴터스 패션, $3 \mathrm{D}$ 디지털 프린팅 패션, $\mathrm{LED}$ 패션, 발광형 패 션, 가변형 패션, 상호작용성 패션, 인터랙티브 의상, 키네틱 아트 등으로 디지털 기술과의 융합을 통해 표 현되고 있는 용어들이 나타나고 있다(Table 1).

그러나 일반적으로 디지털 디자인(digital design) 은 컴퓨터와 소프트웨어를 이용한 디자인을 통칭하 는 용어로 쓰인다("Planning - Digital design competitiveness", 2003). 이에 디지털 문화를 표현한 사이버적 
$<$ Table 1> Term that expresses digital fashion through previous research

\begin{tabular}{|c|c|c|}
\hline & Term & Researcher(year) \\
\hline $\begin{array}{l}\text { Digital age } \\
\text { fashion }\end{array}$ & $\begin{array}{l}\text { Space look, techno-cyber fashion, cyber funk fashion, } \\
\text { futuristic fashion, futurism }\end{array}$ & $\begin{array}{l}\text { Chun(2008), Chun(2010), } \\
\text { Jang \& Hyun(2003), Kim(2003) }\end{array}$ \\
\hline $\begin{array}{l}\text { Digital } \\
\text { fashion }\end{array}$ & $\begin{array}{l}\text { High-tech fashion, intelligent garment, light graffiti } \\
\text { fashion, technology fashion, smart wear, wearable } \\
\text { computer, ubiquitous fashion, 3D digital printing fashion, } \\
\text { LED fashion, illumination fashion, variable fashion, } \\
\text { interactive fashion, kinetic art }\end{array}$ & $\begin{array}{l}\text { Chun(2008), Chun(2010), } \\
\text { Chun \& Ha(2006), Heo \& Lee(2013), } \\
\text { Hyun(2002), Jang \& Hyun(2003), } \\
\text { Kim(2003), Kim(2007), Kwak(2009), } \\
\text { Park \& Lee(2001) }\end{array}$ \\
\hline
\end{tabular}

이고 미래적, 테크노 이미지를 도합하는 광의의 '디 지털 시대의 패션'은 제외하고, 본 연구에서의 "디지 털 패션"은 컴퓨터의 소프트웨어와 하드웨어적 측면 의 디지털 기술을 활용한 패션 디자인을 통칭하는 것 으로 사료되어, 본 연구에서는 디지털 패션의 정의를 재 명명하였다.

이에 따라 선행연구를 통해 디지털 패션을 역사적 으로 고찰해 볼 때 시발점은 1960년대로 볼 수 있다. 1960 년대 컴퓨팅 기기를 분리하여, 의복에 부착한다 는 개념과 함께 웨어러블 컴퓨터가 생겨났다(Park \& Lee, 2001). 최초의 웨어러블 컴퓨터 개념 연구는 1966 년 $\mathrm{PC}$ 를 기반으로 한 $\mathrm{HMD}$ (Head Mounted Display) 를 이반 서덜랜드(Ivan Sutherland)가 설계하여, 현실 과 가상세계가 겹쳐 보이도록 한 것이었다(Park \& Lee, 2001). 의류분야가 아닌 컴퓨터 공학 관련분야 에서 웨어러블 컴퓨터는 처음 등장하여 스마트 웨어 로 발전하였다(Lee, 2005). 이동 환경에서 자유롭게 착용할 수 있도록 제작된 웨어러블 컴퓨터의 일부인 유비쿼터스 패션은 실질적인 의미의 유비쿼터스 연 구가 1988년부터 시작되었다("Ubiguitous Fashion", n.d.). 유비쿼터스 컴퓨팅(ubiquitous computing)이 등 장하고 웨어러블 디바이스와 전자기기가 소형화, 경 량화 되면서, 산업에서 본격적으로 적용이 가능해졌 다("Ubiguitous Computing", n.d.). 의복 안에 내장된 디지털 IT 디바이스들의 융합으로 웨어러블 컴퓨터, 유비쿼터스 패션 등을 비롯한 디지털 패션의 본격적 인 개발이 나타났다.

웨어러블 컴퓨터에 관한 연구는 1990년대에 들어 서면서 정보 기술이 급속히 발전함에 따라 테크놀로 지의 빠른 발전과 더불어 급진전되었다(Park \& Lee, 2001). 1990년대에는 본격적으로 인터넷의 보급과 정
보통신의 발달의 확산으로 과학기술과 패션이 직접 적으로 접목된 사이버 펑크 패션, 그리고 미래 지향 적인 테크노 패션과 디지털 기술이 접목된 다양한 통 신 및 멀티미디어 디바이스가 의복에 내장된 웨어러 블 컴퓨터가 많이 나타났다. 초기에 개발된 웨어러블 컴퓨터는 특정장소에서만 컴퓨팅이 가능하도록 전선 으로 연결되어 장소의 제약이 있었으나, 현재에는 와 이어리스(wireless)를 통해 발달된 디지털 기술이 접 목되어 장소 제약 없이 유비쿼터스 패션의 웨어러블 컴퓨터가 활용되고 있다.

발전된 기술로 인해 웨어러블 컴퓨터에도 기능성 이 포함되기 시작하였는데, 1990년대 중반 미국에서 기능성 웨어러블 컴퓨터를 군사용으로 처음 개발되 었다. 기능성 웨어러블 컴퓨터는 고기능성 섬유에 초 소형 컴퓨터 칩, 디지털 센서 등을 내장해서, 외부 자 극을 감지하고 반응할 수 있고, 의복 자체가 모든 것 을 알아서 처리하는 미래형 최첨단 의복이다("Smart Wear", n.d.). 디지털 시대의 대표적인 기술의 융합으 로 정보기술(IT) - 나노기술(NT) - 바이오기술(BT) 환경기술(ET) 등이 결합되어 새로운 개념의 기능성 스마트 웨어를 나타내고 있다. 패션분야에 컴퓨팅 환 경을 접목시킨 웨어러블 컴퓨터 패션은 다양한 기능 의 지능성을 가진 인텔리전트 의복, 그리고 신 섬유 디지털 기술이 접목된 스마트 웨어 등으로 다양하게 계속해서 개발이 진행되고 있다.

이후 2000 년대에 들어 꾸준히 기능성이 포함된 실 험적이고, 디지털 기술을 활용한 디지털 패션이 나타 나고 있다. 디지털 기술의 발달은 패션분야에도 많은 영향을 주고 있으며, 패션 브랜드와 다양한 분야에서 의 이러한 기술의 융합이 활발하게 나타나고 있다. 현재 디지털 기술은 자동화된 봉제 시스템과 패션 
$\mathrm{CAD}$ 디자인 프로그램 등의 의복 제작 설비와 패션 섬유에서 있어서도 신소재, 스마트 섬유, 기능성 섬유 등으로 다양하게 발전되고 개발하고 있다. 디지털화 를 나타내는 컴퓨터 그래픽의 현시성은 패션 디자이 너의 컨셉 의도를 즉시 시각화가 가능하며, 이는 곧 작업 과정을 통해 완성된 디자인 결과물을 미리 확인 할 수 있게 한다. 그리고 디자인의 작업 과정을 체계 적으로 전개할 수 있으며, 이러한 디지털 디자인 결 과물을 저장시켜, 다음 디자인 작업에 자료로 활용할 수 있는 이점을 가진다. 디지털 패션은 시각적인 요 소뿐 아니라, 기능적인 요소까지 포함된 패션과 비디 오 스크린을 통해 디지털 이미지를 텍스타일에 표현 한 패션, 기능성 신소재로 만든 패션, 가상적인 $3 \mathrm{D}$ 패 션 등 디지털 기술의 협업을 통한 패션의 개념이 발 전되어 다양하게 나타나고 있다.

\section{Results and Discussion}

\section{The case study of digital fashion design}

본 연구에서 디지털 패션은 컴퓨터의 디지털 툴과 기술을 활용한 패션 디자인을 통칭하는 것으로, 디지 털 소프트웨어 프로그램을 사용한 디자인과 하드웨 어 디바이스를 사용한 웨어러블 컴퓨터 디자인으로 나누어 분석하였다. 이에 세부적인 요소는 DTP(Digital Textile Printing), 설치형(installation), 3D 프린팅(3D printing)이 나타난 소프트웨어 측면의 컴퓨터 그래픽 (Computer Graphic: CG)과 웨어러블 컴퓨터(wearable computer)를 포함한 하드웨어 측면의 디지털 디바이 스(digital device)로 분류되었다. 디지털 패션디자인은 디지털 툴과 기술을 활용하였기 때문에 컴퓨터 프로 그램을 통해 디지털 패션 프로세스의 과정에서 나타 난 디자인과 완성된 결과물의 디자인을 볼 수 있다.

디지털 패션디자인에 있어서 컴퓨터 그래픽은 소프 트웨어 프로그램을 활용하여, 다양한 디지털 그래픽 디자인을 하고 있다. DTP는 디지털 이미지의 특성인 변형 가능한 무한 복제성을 통해 손쉬운 반복이 가능 해졌다. 반복과 복제된 디자인은 원본과 관계없이 품 질이 저하되지 않으며, 디지털 툴을 활용하여 텍스타 일 디자인을 할 수 있다. 이처럼 짧은 시간에 다양한 기능을 활용하여, 수많은 디자인을 확장시킬 수 있다 (Fig. 1). 그리고 디지털화 된 파이선(python) 패턴을
픽셀화하여 디지털 방식으로 인쇄하여 디자인하고 있 다(Clarke \& Harris, 2012)(Fig. 2). 설치형은 기존에 표 현할 수 없었던 유동적인 디지털 이미지의 디자인을 텍스타일에 표현할 수 있다. 의복의 표면에 디지털 컬 러와 컴퓨터 그래픽이 빛을 통해 유동적인 비물질 형 태로 나타낼 수 있으며, 〈Fig. 3, 4〉와 같이 디자인한 디지털 이미지를 빔 프로젝트를 통해 의복의 표면에 표현하고 있다. 그리고 2013년 이후 빠르게 발전하고 있는 $3 \mathrm{D}$ 프린팅을 활용하여, 패션분야에서도 소프트 웨어 프로그램을 통해 디자인한 의복을 $3 \mathrm{D}$ 형태로 바 로 프린팅해 볼 수 있다. 모니터 속에서의 디자인뿐 아 니라, 의복의 재질과 조형성도 함께 볼 수 있다. 일반 의복의 재질이 아닌 플라스틱, 고무, 금속 재질 등과 같은 다양한 재질을 활용하여 디지털 패션을 나타내기 도 하며, 기존에는 표현하기 힘들었던 투명성을 플라 스틱 재질을 통해 마치 물이 뿌려지는 듯한 느낌을 표 현하여 나타내기도 하였다(Fig. 5). 또한 텍스타일 디 자인에까지도 $3 \mathrm{D}$ 프린팅을 활용하고 있다(Fig. 6). 그 리고 $2016 \mathrm{~F} / \mathrm{W}$ 컬렉션에서는 사람 손을 실제로 3D 스캐너로 스캔한 후 그대로 $3 \mathrm{D}$ 프린터로 출력하여, 검 은 해골 무늬의 모티브를 인체 공학적인 디자인의 우 산 핸들을 나타냈다. 실제로 판매되는 명품 한정판 $3 \mathrm{D}$ 프린팅 우산을 선보였다(Fig. 7). 이렇게 컴퓨터의 소 프트웨어 프로그램을 활용하여, $2 \mathrm{D}$ 형태의 텍스타일 디자인부터 $3 \mathrm{D}$ 형태의 조형적인 디자인까지 모두 디 지털 패션디자인으로 표현할 수 있다.

하드웨어 측면에서 디지털 디바이스의 웨어러블 컴퓨터는 컴퓨터 자체를 연결하여 시스템을 입을 수 있도록 만든 것으로 컴퓨터를 입는다는 의미를 가지 고 있다. 웨어러블 컴퓨터는 컴퓨팅 기기를 분리하여 의복에 부착한다는 개념이 생겨났으며, 작게는 패션 액세서리 아이템부터 크게는 의복 전체의 웨어러블 디지털 디바이스가 등장하였다. 또한 최근에는 인체 에 반응하여 상호작용하는 기능성 텍스타일과 디지 털 기기가 센서를 통해 디지털 패션디자인으로 나타 나고 있다. 〈Fig. 8〉은 뉴욕 패션 위크에서 공개된 생 체 인식 제어 의류로 컴퓨터 하드웨어인 Intel Curie Module과 신체 열, 땀 및 호흡을 감지하는 센서, 아드 레날린을 나타내는 웨어러블 기기를 사용하여 설계 되었다. 새로운 소재, 감지 및 컴퓨팅 기술이 등장하 여, 센서에 연결된 Intel Curie 디지털 하드웨어 모듈 
을 통해 아드레날린 드레스(Adrenalin Dress)는 착용 자의 호흡, 땀 및 체온을 감지할 수 있다. $3 \mathrm{D}$ 디자인 작업을 수행한 패션 웨어로서 $3 \mathrm{D}$ 프린팅을 활용해 드레스의 뒤쪽의 장식에 있는 팽창 및 수축 장치는 탄소 섬유로 만들어졌다(Kaplan, 2015). 또한 여러 가 지 기능의 디지털 기기 부품을 사용자의 편의에 맞게 의복에 배치하여, 이동이 자유롭다(Fig. 9). 이러한 다 양한 기능성을 포함하여 스마트한 디지털 패션디자 인을 보여주고 있는 디지털 디바이스의 웨어러블 컴 퓨터 또한 의복의 텍스타일과 조형적인 디자인 모두 볼 수 있다(Fig. 10).

디지털 패션디자인 유형을 정리하여 보면 〈Table 2)와 같다.

2. Analysis of media aesthetic perspective in digital fashion

디지털 매체의 경향에서 나타난 디지털 이미지의 미학적 관점을 통해 앞서 연구한 디지털 패션을 표현 하는 생성의 방식과 수용에도 많은 변화가 나타나고 있다. 디지털 패션에서 나타난 미학적 특성은 매체 철학자들의 디지털 이미지에 대한 미학적 사유에 따 라 '생성의 관점을 통해 본 디지털 패션'과 '수용의 관점을 통해 본 디지털 패션’으로 분석하였다. 이에 대한 매체 미학적 관점에서의 논의가 디지털 매체인 컴퓨터 프로그램에 의해 생성되고 수용되는 디지털 이미지에 관련된 것이므로 디지털 패션디자인 유형 중 소프트웨어 측면의 컴퓨터 그래픽을 활용한 디지 털 패션에 국한시켜 분석하였다.

1) The digital fashion viewed through the perspective of creation

생성의 관점을 통해 본 디지털 패션의 미학적 특성 은 매체에 의해 생성된 디지털 이미지에 관한 존재론 적 관점과 함께 연결하여 볼 수 있다. 매체 철학자들 의 미학적 사유를 통해 생성의 관점으로 연구되어지 고 있는 디지털 이미지의 특성은 원본성이 의미가 없 고, 일시성과 반복성이 연결되어 있다. 실제 존재하지 않는 개체를 생성하여 새로운 가상 이미지를 표현하 고, 하이퍼 리얼리티 이미지를 나타내고 있다. 매체 철학자들의 의해 미학적 논의가 활발하게 이어지고 있는 이미지가 매체에 의해 생성되기 시작하면서 원
본성의 의미가 아우라의 몰락에 의해 사라졌듯이, 디 지털 이미지가 활용되어 나타난 디지털 패션에서의 원본성 또한 의미가 없어졌다. 디지털 이미지가 패션 에 적용되었을 때에도 변형 가능한 복제성에 의해서 무한 반복되어 디자인될 수 있고, 원본의 품질이 훼 손되거나 저하되지 않는다. 이러한 디지털 이미지가 생성되는 기술적인 이점이 패션에도 그대로 반영된 것으로 보인다. 또한 컴퓨터 그래픽 프로그램 툴을 사용하여, 이미지를 합성하거나 변형하고 효과를 주 어 전혀 다른 이미지의 디자인을 짧은 시간에 손쉽게 생성되기도 한다(Fig. 11). 그리고 모델의 이미지를 반복, 복제와 좌우 대칭 효과를 활용하여 패션 광고 에 나타내기도 한다(Fig. 12).

디지털 매체 시대의 특징이 된 시뮬라시옹을 나타 내는 비물질적으로 나타난 가상 이미지는 빛을 활용 하여 디지털 컬러와 그래픽을 디지털 패션 이미지로 생성하여, 기존의 의복 형태가 아닌 유동적인 비물질 가상 형태로 의복의 표면에 디지털 그래피티 디자인 으로 표현되기도 한다. 이처럼 물질적인 형태의 의복 이 비물질로 구성된 새로운 의복 형태로도 나타나고 있다. 이렇게 매체의 변화에 따라 의복의 텍스타일 디자인과 형태도 변화하고 있다. 이는 디지털 기술을 활용하여 이전에는 볼 수 없었던 디지털 컬러와 컴퓨 터 그래픽이 다양하고 창조적으로 의복의 표면에 표 현된 것이다. 디지털 컬러는 RGB(Red, Green, Blue) 의 세 가지 컬러를 빛으로 조절하여, 기존에는 낼 수 없었던 컬러를 디자인 의도에 따라 다양하게 조합할 수 있다. 또한 의복은 실체가 있는 물질을 바탕으로 하여 인체에 착장되어야만 의미를 부여받는 대상이 었지만, 디지털 매체 시대에는 비트라는 비물질로 인 해 합성과 콜라주를 통해 새로운 디지털 패션디자인 의 양식을 보여주고 있다. 〈Fig. 13〉과 같이 모델 주 위에 빛을 투사하여, 'light graffiti' 라는 디지털 그래 피티 디자인을 표현하고 있다(Quinn, 2011). 그리고 2016년에는 〈Fig. 14〉와 같이 가상현실 공간 속에서 $2 \mathrm{D}$ 가 아닌 $3 \mathrm{D}$ 입체적인 형태의 디자인을 표현한 디 지털 패션이 나타나고 있다.

디지털 패션 이미지는 어떠한 실제 대상을 모방하 여 디자인한 이미지뿐 아니라. 현실에 존재하지 않음 에도 불구하고, 실재보다 더 실재와 같은 가상의 이 미지를 생성하여 언캐니(uncanny)한 감성을 가지고 
$<$ Table 2> The case study of Digital Fashion Design

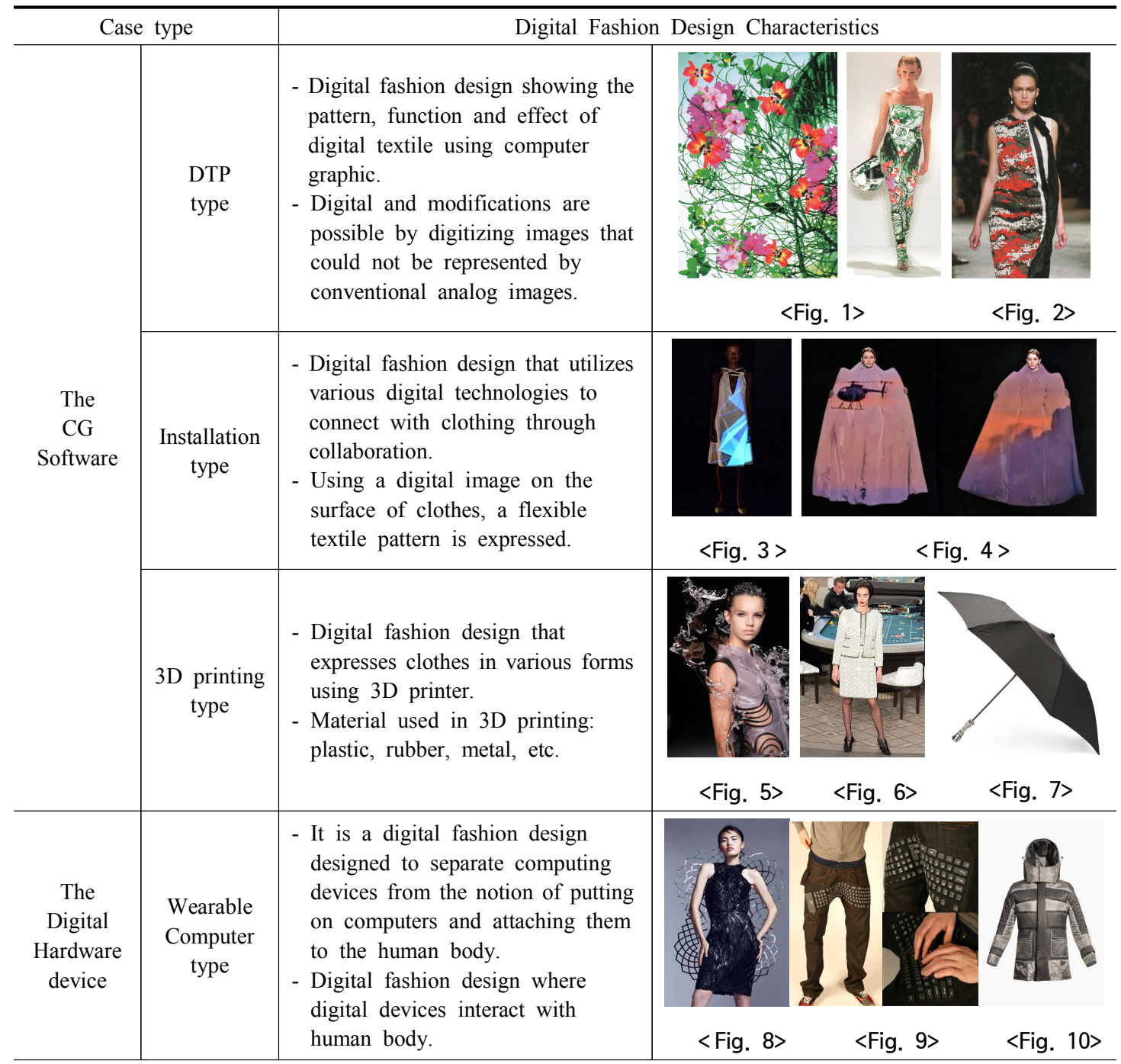

<Fig. 1> Michiko Koshino. 04 S/S. From. Clarke \& Harris. (2012). p.175.

<Fig. 2> Prada. 07 S/S. From. Clarke \& Harris. (2012). p.108.

<Fig. 3> Hamish Morrow. 04 S/S. From. Hamish morrow. (n.d.). www.hamishmorrow.com

<Fig. 4> Victor \& Rolf. 02 F/W. From. Vogue. (2002). http://www.vogue.com

<Fig. 5> Iris van herpen. $11 \mathrm{~S} / \mathrm{S}$. From. Iris van herpen. (2010). http://www.irisvanherpen.com

<Fig. 6> Chanel. 15 F/W. From. Vogue. (2015). http://www.vogue.com

<Fig. 7> Alexander McQueen. 16 F/W. From. Shin. (2016). http://ktech21.com

<Fig. 8> Francis Bitonti. $16 \mathrm{~S} / \mathrm{S}$. From. Kaplan. (2015). http://q.intel.com

<Fig. 9> Erik De Nijs. Beauty and the Geek'. From. James. (2008). http://www.yankodesign.com

<Fig. 10> Kunihiko Morinaga. From. Johnny. (2014). http://www.spoon-tamago.com

있다. 여기서 언캐니란 실재도 아니고 가상도 아닌 유령과 같은 존재가 발산하는 섬뜩한 느낌을 의미하 며, 디지털 가상에는 언캐니 특성이 있다(Chin, 2014b).
언캐니한 디지털 이미지는 실험적인 디자인을 추구 하는 패션 디자이너의 작업에 활용되고 있었다(Fig. 15). 또한 디지털 이미지를 극사실적 표현으로 실물 
과 같이 보이게 하여, 진짜와 혼동하여 착각할 수 있 는 트롱프 뢰유(Trompe-l'oeil) 기법으로 텍스타일 디 자인에 효과를 주기도 한다(Fig. 16).

이러한 가상적인 디지털 이미지는 DTP 디자인을 통해서 다양한 형태의 텍스타일로 나타낼 수 있을 뿐 아니라, 모니터 속의 디지털 패션 이미지가 $3 \mathrm{D}$ 프린 팅을 통해 디지털 패션디자인으로 표현되고 있다. $3 \mathrm{D}$ 프린팅을 활용하여 기존의 의복 형태가 아닌 실존하 지 않는 가상 이미지를 디지털 매체를 통해 조형화로 나타내기도 하며, 의복의 재질 또한 다양한 형태의 재 질이 나타나고 있다(Fig. 17, 18).

요컨대, 철학자들의 디지털 매체 미학적 사유를 생 성의 관점에서 디지털 패션을 분석한 결과, 무한 반 복성과 변형 가능한 복제성, 유동적인 이미지의 가상 화, 현실에 존재하지 않는 가상 이미지, 실재보다 더 실재와 같은 이미지에 나타난 언캐니, 가상적인 이미 지의 조형화 특성이 나타났다. 생성의 관점에서 본 디지털 패션의 미학적 특성에 대한 사례 분석을 정리 하여 보면〈Table 3〉과 같다.

2) The digital fashion viewed through the perspective of acceptance

수용의 관점을 통해 본 디지털 패션의 미학적 특성 은 매체에 의해 생성된 디지털 이미지가 수용자에게 시각적 촉각성을 통해 새롭게 지각되었다. 매체 철학 자들의 미학적 사유를 통해 생성의 관점으로 연구되 어지고 있는 디지털 이미지의 특성은 시각적 촉각성 을 통해 새로운 지각방식을 체험하고, 가상 이미지 공간에 몰입되어 상호작용하여, 파타피직스를 경험하 게 된다. 시공간의 제한이 없는 유비쿼터스 공간에서 가상 이미지를 나타내고 있다. 실험적인 디자인을 추 구하는 패션 디자이너들은 디지털 이미지의 시각적 촉각이 유발하는 연상 작용을 패션에 활용하여 새로 운 예술적 창의성을 표현하고 있으며, 이를 통해 수 용자 입장에서는 시각적 촉각성을 통해 몰입을 체험 하게 된다. 수용자가 $3 \mathrm{D}$ 안경을 착용함으로써 입체적 으로 나타나는 텍스타일 무늬의 디지털 패션이 완성 되는 디자인을 통해, 컬렉션을 감상하는 관객에게 입 체감 있는 디지털 패션 이미지를 보여주고 있다(Fig. 19). 디지털 기술과 패션의 융합을 통해 휴대폰의 섬 광에 반응하는 감광 직물을 활용하여, 다채로운 패턴
의 기하학적 프린트를 관람하는 수용자의 휴대폰 조 명 빛에 의해 반응하는 형광 패턴이 상호작용되어 다 양한 색채로 표현되는 디지털 패션도 나타나고 있다 (Fig. 20). 이는 기존의 패션을 관조적 방식으로 관람 하였다면, 디지털 패션은 수용자 입장에서 시각적 관 람뿐 아니라, 수용과정에서 이미지 안으로 들어가 몰 입을 통해 직접적으로 체험하는 듯한 경험을 한다. 이처럼 디지털 패션은 시각적 표현 매체를 넘어 다감 각적 표현 매체로서, 새로운 미적 창작의 가능성을 보여주고 있다.

이러한 과정은 디지털 패션디자인뿐 아니라, 수용 자 관점에서 패션 컬렉션 무대와 같은 다양한 패션 공간에서 가상과 실재가 중첩된 파타피직스를 볼 수 있다. 실제 모델과 함께 등장하는 홀로그래피 패션쇼 (Holographic Fashion Show)는 실재와 가상이 공존하 여 나타난 무대이다. 디지털 매체를 활용하여 비물질 적인 $3 \mathrm{D}$ 입체 홀로그래피 영상을 디지털 입체 사운 드와 함께 청각을 극대화시켜 수용자의 시각을 통해 시청각뿐 아니라, 촉각을 느낄 수 있는 패션디자인과 유기적인 디지털 가상 이미지를 패션쇼 무대에 등장 하는 연출을 하였다(Fig. 21, 22). 디지털 패션에 있어 서 가상과 실재가 중첩되어 공존하는 파타피직스는 앞으로도 다양한 형태의 미적 특성으로 발전될 것으 로 보인다.

디지털 편집 기술을 통한 시-공간의 해체와 재구 성을 통한 패션쇼 무대 공간에도 그대로 반영되어, 가상 퍼포먼스와 시각적 유희를 즐길 수 있는 패션 컬렉션 무대가 나타났다. 2000년대 이후 디지털 매체 를 통해 패션 컬렉션 시청이 전 세계에서 동시에 실 시간으로 가능해졌다(Fig. 23). 가상과 실재가 공존하 여 중첩된 공간에서 디지털 편집 기술을 통해 새로운 시간 체계의 원격현전을 시·공간의 제한 없이 상호작 용하여 파타피직스를 체험할 수 있다. 그리고 2010년 착용 가능한 증강현실을 소개하면서 패션분야에서의 가능성을 보여주었으며, 옷에 그려진 심볼을 통해 카 메라 앞에서 $3 \mathrm{D}$ 애니메이션으로 구현되는 프로젝트 가 실현되었다(Fig. 24).

디지털 패션 이미지는 컴퓨터 그래픽 프로그램을 통해 가상의 디지털 이미지가 디자이너에 의해 생성 되어, 시각적으로 수용자에 의해 인식됨과 동시에 디 지털 가상공간을 실재로 착각하고 상호작용하게 된 
<Table 3> Case analysis of aesthetic characteristics in Digital Fashion -1

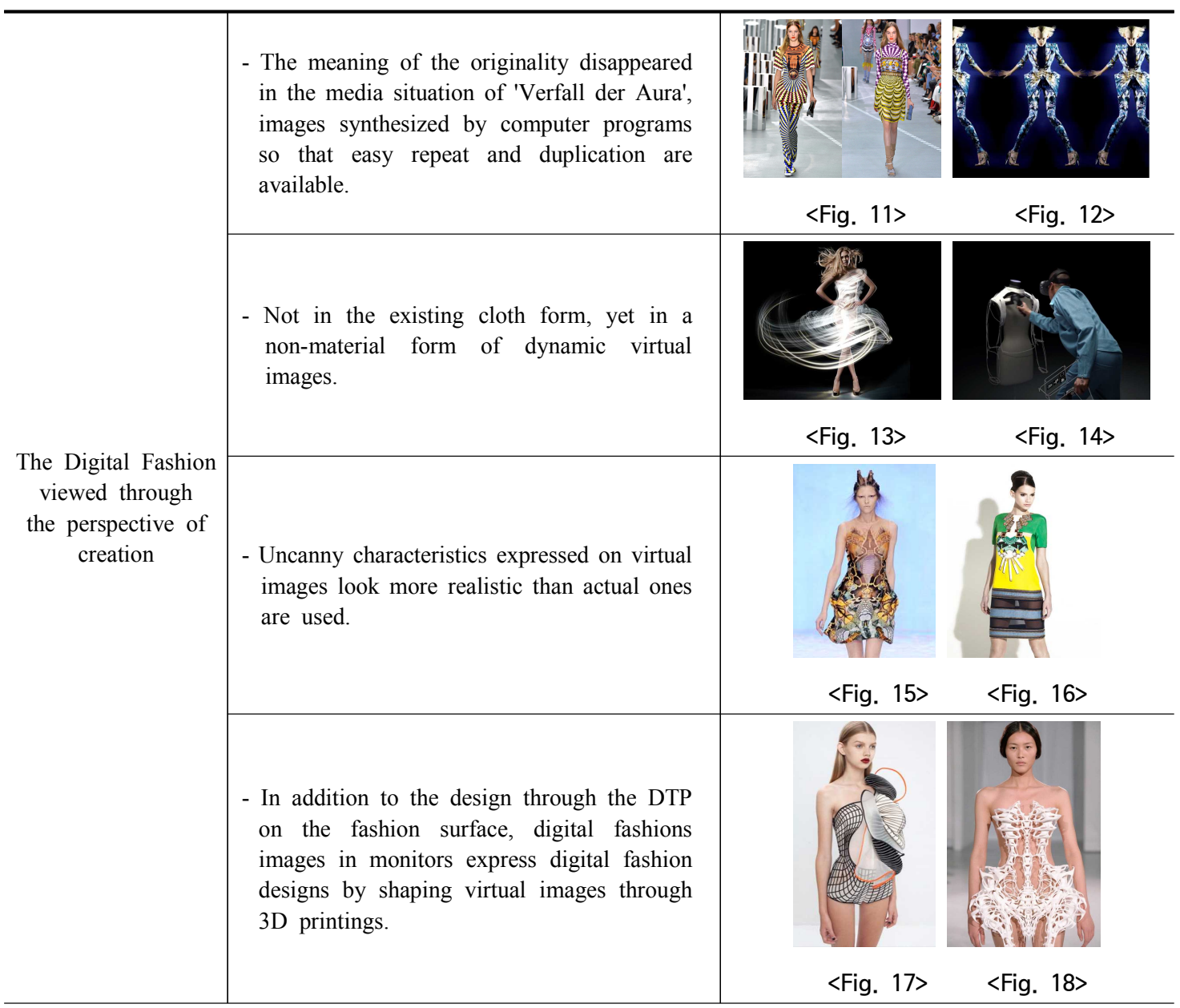

<Fig. 11> Mary Katrantzou. 17 S/S. From. Mary Katrantzou. (n.d.b). http://marykatrantzou.com

<Fig. 12> Alexander McQueen. 10 S/S. From. Vogue. (2009a). http://www.vogue.com

$<$ Fig. 13> Photographer Atton Conrad. From. Atton Conrad. (n.d.). http://www.attonconrad.com

<Fig. 14> Tilt brush by Google. From. Google. (2016). https://www.tiltbrush.com

<Fig. 15> Alexander McQueen. 10 S/S. From. Vogue. (2009b). http://www.vogue.com

<Fig. 16> Mary Katrantzou. 09 S/S. From. Mary Katrantzou. (n.d.a). http://marykatrantzou.com

$<$ Fig. 17> Noa Raviv. From. Noa Raviv. (n.d.). http://www.noaraviv.com

<Fig. 18> Iris van herpen. $11 \mathrm{~F} / \mathrm{W}$. From. Iris van herpen. (2011). http://www.irisvanherpen.com

다. 이는 가상현실뿐 아니라, 증강현실도 나타나고 있 는데, 가상현실은 현실을 가상의 환경에 몰입시킨다 면, 증강현실은 가상을 불러와 현실의 층위에 중첩시 킨다. 디지털 패션에서의 증강현실은 $3 \mathrm{D}$ 아바타를 이 용하여, 가상 코디네이션을 시뮬레이션할 수 있다. 3 차원 가상 피팅 솔루션으로 수용자의 신체 사이즈를 측정하여 실시간으로 스크린을 통해 $3 \mathrm{D}$ 의상 피팅을
보여준다. 최근 국내에도 백화점 및 쇼핑몰 등에서 도입하여, $3 \mathrm{D}$ 가상 피팅 서비스를 상용화하고 있으 며, 스마트폰 앱을 통해 활용되고 있다(Fig. 25, 26). 디지털 기술의 발전에 따라 패션은 기존의 완성되고 고정된 형태로 정적인 미적 기준에 따른 예술형식이 아니라, 이제는 더 이상 완성된 결과물이 아닌 유동적 이고 역동적으로 변화하고, 수용자와 상호작용을 할 
수 있게 되었다.

요컨대 철학자들의 디지털 매체 미학적 사유를 수 용의 관점에서 디지털 패션을 분석한 결과, 시각적 촉각성의 몰입화, 가상과 실재가 중첩된 파타피직스, 디지털 편집 기술을 통해 새로운 시간 체계의 원격현 전, 증강현실을 통한 상호작용성 특성이 나타났다. 수
용의 관점에서 본 디지털 패션의 미학적 특성에 대한 사례 분석을 정리하여 보면〈Table 4〉와 같다.

\section{Conclusion}

21세기는 지식정보화 사회로 디지털 매체가 융복

$<$ Table 4> Case analysis of aesthetic characteristics in Digital Fashion -2

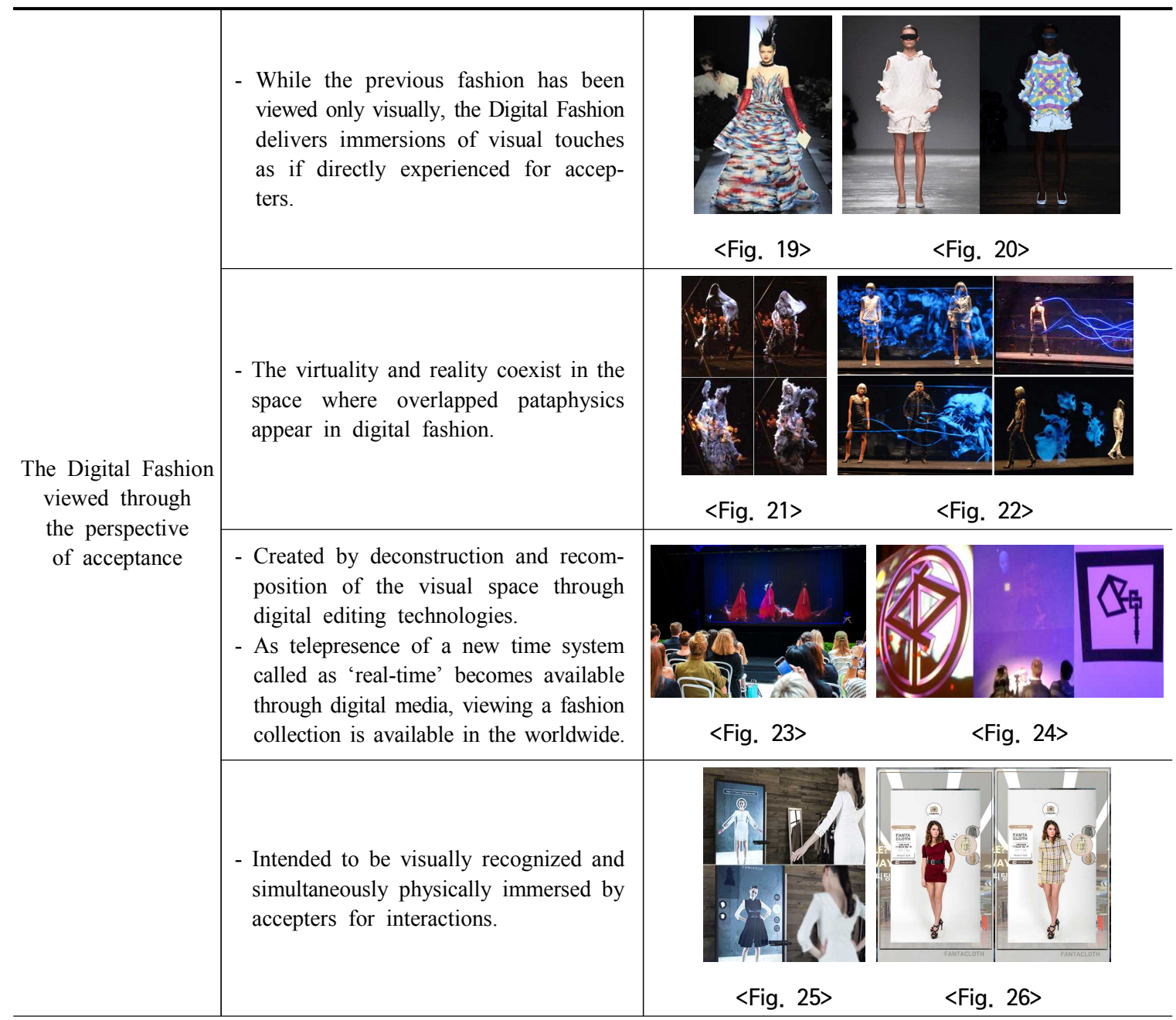

<Fig. 19> Jean Paul Gaultier. 11 S/S. From. Vogue. (2011). http://www.vogue.com

<Fig. 20> Kunihiko Morinaga. 16 S/S. From. Battista. (2015). http://www.irenebrination.typepad.com

<Fig. 21> Alexander McQueen. 06 F/W. From. Vogue. (2006). http://www.vogue.co.uk

<Fig. 22> Diesel. 'Liquid Space'. 08 S/S. From. FT. (n.d.). http://www.fashiontrendsetter.com

<Fig. 23> Cassette Playa Fashion Show. From. Cassette. (2012). http://www.cassette.com.au

<Fig. 24> Cassette Playa AR Fashion Show. From. SDN. (2010). http://www.samsungdesign.net

<Fig. 25> FX Mirror virtual fitting. From. Fxmirror. (n.d.). http://fxmirror.net

<Fig. 26> Fantacloth virtual fitting APP. From. Fantacloth. (n.d.). http://fantacloth.com 
합을 통해 중요하게 나타나고 있다. 디지털 기술의 발전은 패션분야에서 표현할 수 없었던 것을 가능하 게 하였다. 디지털 매체에 의해 생성된 디지털 이미 지는 사회문화적으로 큰 영향력을 행사하고 있다. 이 에 본 연구는 디지털 매체의 경향에서 나타난 디지털 이미지를 매체 미학 철학자들의 미학적 관점에서 디 지털 패션을 분석하였다.

선행연구를 바탕으로 나타난 디지털 패션은 디지 털 시대의 패션과 디지털 패션이 혼용되어 사용되고 있으며, 본 연구에서의 디지털 패션은 디지털 시대의 패션을 제외하고, 컴퓨터의 소프트웨어와 하드웨어적 측면의 디지털 기술을 활용한 패션디자인을 통칭하 는 것으로 사료되어, 이에“디지털 패션”이라고 재 명 명하였다. 디지털 패션디자인은 디지털 기술이 직접 적으로 반영된 소프트웨어 측면의 컴퓨터 그래픽과 하드웨어 측면의 디지털 디바이스로 분류되었으며, 소 프트웨어의 컴퓨터 그래픽에 나타난 요소로는 DTP, 설 치형, $3 \mathrm{D}$ 프린팅이며, 디지털 디바이스는 웨어러블 컴퓨터를 포함하고 있다.

이렇게 정의된 디지털 패션에서 나타난 매체 미학 적 특성은 매체 철학자들의 디지털 이미지에 대한 미 학적 사유에 따라 "생성의 관점을 통해 본 디지털 패 션”과 “수용의 관점을 통해 본 디지털 패션”으로 나 누어 분석하였다. 디지털 패션에 나타난 생성의 관점 에서의 미학적 특성은 무한 반복성과 변형 가능한 복 제성, 유동적인 이미지의 가상화, 현실에 존재하지 않 는 가상 이미지, 실재보다 더 실재와 같은 이미지에 나타난 언캐니, 가상적인 이미지의 조형화로 나타났 다. 디지털 패션에 나타난 수용의 관점에서의 미학적 특성은 시각적 촉각성의 몰입화, 가상과 실재가 중첩 된 파타피직스, 디지털 편집 기술을 통해 새로운 시 간 체계의 원격현전, 증강현실을 통한 상호작용성의 파타피직스로 나타났다.

디지털 패션은 기존의 방식과 달리 완성된 결과물 뿐 아니라, 생성되는 과정 또한 중요하다. 디지털 매 체에 의해 생성된 과정들이 또 다른 디지털 패션 이 미지의 결과물이 될 수 있기 때문이다. 생성된 이후 완성된 결과물로 끝나는 것이 아니라, 수용하는 입장 에서 상호작용을 이룬다. 디지털 패션을 수용하는 관 점에서는 디자인뿐 아니라, 패션쇼 무대와 $3 \mathrm{D}$ 가상 패션쇼 그리고 가상 코디 등으로 패션분야의 다양한
부분에서 나타나고 있다. 패션디자인은 물질을 바탕 으로 인체 위에 착장되기 때문에 비물질을 근간으로 디지털 그래픽을 활용하여 완벽히 디지털화될 수 없 다는 점에 한계가 있었으나, 패션과 디지털 기술의 융합을 통해 $3 \mathrm{D}$ 가상 코디, 패션쇼 무대 퍼포먼스 등 에서 비물질적으로 나타났다. 디지털 패션은 디지털 매체와의 융합으로 인해 계속적으로 발달되고, 발전 되어 더 중요한 영향을 미치게 될 것이다. 앞으로 패 션디자이너들은 디지털 시대에 맞추어 디지털 매체 를 도구이자 표현의 수단으로써 적극적으로 활용하 여, 디지털 패션에 실험적이고, 퍼포먼스적인 디자인 과 더불어 더 새로운 조형성을 표현해야 할 것으로 보인다. 또한 디지털 패션은 일상적으로 착용이 가능 하고, 대량 생산되어 대중화 될 수 있는 패션으로 발 전되어 개발되어야 할 것이다. 디지털 매체의 발전과 함께 앞으로도 계속해서 매체 미학적 관점에서 디지 털 패션에 관한 연구는 꾸준히 필요하며, 이후 빠르 게 변화하고 발전하고 있는 디지털 기술을 반영한 디 지털 패션 분석에 대한 연구가 후속적으로 이루어져 야 할 것으로 사료된다.

\section{References}

Atton Conrad. (n.d.). Light painted dresses. Retrieved August 6, 2015, from http://www.attonconrad.com/ light-painted-dresses

Battista, A. (2015, September 30). Reflect the existing reality to create a new one: Anrealage S/S 16 [Blog Post]. Retrieved May 16, 2016, from http:// www.irenebrination.typepad.com/irenebrination_n otes_on_a/2015/09/anrealage-ss-16.html

Cassette. (2012). Holographic fashion show. Retrieved August 6, 2015, from http://www.cassette.com.au/ our-work/holographic-fashion-show

Chin, J. K. (2014a). 이미지 인문학 1: 현실과 가상이 중첩하는 파타피직스의 세계 [Image humanities 1]. Seoul: A thousand years of imagination.

Chin, J. K. (2014b). 이미지 인문학 2: 섬뜩한 아름다 움을 창조하는 언캐니의 세계 [Image humanities 2]. Seoul: A thousand years of imagination.

Chun, J. H., \& Ha, J. S. (2006). A study on 
formative features of fashion design in digital era. Journal of the Korean Society of Clothing and Textiles, 30(11), 1560-1571.

Chun, J.-H. (2010). The digital characteristics of modern fashion based on the perspectives of cultural studies. Unpublished doctoral dissertation, Seoul National University, Seoul, Korea.

Chun. J.-H. (2008). A study of digital image in fashion design: Regarding Hussein Chalayan's design. Unpublished master's thesis, Hongik University, Seoul, Korea.

Clarke, S. E. B., \& Harris, J. (2012). Digital visions for fashion + textiles: Made in code. New York: Thames \& Hudson.

Digital image. (n.d.). In Daum online dictionaries. Retrieved July 6, 2015, from http://100.daum.net/ encyclopedia/view/43XXX9300166

Digital. (n.d.). In Doopedia. Retrieved September 24, 2014, from http://www.doopedia.co.kr/doopedia/ master/master.do? method=view\&MAS IDX $=10$ 1013000896114

Fantacloth. (n.d.). Fantacloth. Retrieved May 30, 2016, From http://fantacloth.com

Flusser, V. (1999). 사진의 철학을 위하여 [For the philosophy of photography]. (J. S. Yoon, Trans.). Seoul: Communicationbooks. (Original work published 1994)

FT. (n.d.). Diesel Spring Summer 2008: Liquid Space. Retrieved May 30, 2016, from http://www.fashion trendsetter.com/content/fashion_shows/Diesel-Liq uid-Space-p3.html

Fxmirror. (n.d.). Main features. Retrieved May 30, 2016, http://fxmirror.net/kr/features

Google. (2016, May 3). Tilt brush: Painting from a new perspective. Retrieved May 3, 2016, from https:// www.tiltbrush.com

Hamish morrow. (n.d.). Archive. Retrieved August 6, 2015, from www.hamishmorrow.com/archive/ shows-5

Heo, S. Y., \& Lee. Y. H. (2013). The interaction expressed in 21st century's digital fashion: Focused on the luminescence digital fashion designs. Journal of the Korean Society of Costume, 63(4), 17-29. doi:10.7233/jksc.2013.63.4.017

Hyun, M.-K. (2002). Design of future digital clothing. Unpublished master's thesis, Jeju National University, Jeju Special Self-Governing Province, Korea.

Iris van herpen. (2010, July). Crystallization. Retrieved September 16, 2015, from http://www.irisvanherpen. com

Iris van herpen. (2011, July). Capriole. Retrieved September 16, 2015, from http://www.irisvanherpen. com

James, A. (2008, April 22). Beauty is skin deep, Geekness is to the core... Yonko Design, Retrieved August 6, 2015, from http://www.yankodesign.com/ 2008/04/22/beauty-is-skin-deep-geekness-is-to-the -core

Jang, A.-R., \& Hyun, M.-K. (2003). Digital paradigm depicted on digital clothing. Journal of the Korean Society of Costume, 53(4), 31-47.

Jin, K. A. (2014). 매체 미학과 영상 이미지 [Media aesthetics and visual images]. Seoul: Communicationbooks.

Johnny. (2014, April 28). Radio frequency shielding fashion to help you focus. Spoon \& Tamago, Retrieved August 6, 2015, from http://www.spoontamago.com/2014/04/28/radio-frequency-shielding -fashion-to-help-you-focus

Jung, H. H. (2012). A study on the aesthetic characteristics of digital art. Journal of Digital Design, 12(1), 203-212.

Kaplan, K. (2015, September 30). Future tech fashion styles hit NYFW runway. Intel, Retrieved September 16, 2016, from https://iq.intel.com/future-tech-fashion -styles-hit-nyfw-runway

Kim, J.-E. (2007). A study on digital clothing design by characteristics of ubiquitous environment. Journal of the Korean Society of Costume, 57(3), 23-36.

Kim, J.-H. (2005). A study on digital culture phenomenon shown in the modernly fashion design. Fashion \& Textile Research Journal, 7(2), 143-152. 
Kim, Y.-K. (2010). A study of organic fashion design according to change in the paradigm of the digital age. Unpublished doctoral dissertation, Kyunghee University, Seoul, Korea.

Kim. H.-S. (2003). A study of cyber-feminism in fashion in the digital era. Unpublished doctoral dissertation, Sookmyung Women's University, Seoul, Korea.

Kwak, T. G. (2009). The study on the development trend of the times toward digital clothing. Journal of the Korean Society of Costume, 59(4), 111-125.

Kwon, S. H. (2008). 디지털 문화론 [Digital culture, media, communication \& future]. Seoul: Sungkyunkwan University Press.

Lee, J. H. (2005, April). Ubiquitous와 생활환경: 스 마트 의류를 중심으로 [Ubiquitous and living environment]. Proceedings of KHEA Conference, Seoul, 10-18.

Lee, M. J. (2003). A study on the effect of the digital communication culture on modern fashion. Unpublished doctoral dissertation, Yonsei University, Seoul, Korea.

Lee, W. G. (2004). 디지털화 영상과 가상공간. '새로운 예술'의 지평을 위하여 [Digitized image \& virtual space]. Seoul: Yonsei University Press.

Mary Katrantzou. (n.d.a). Runway Looks: Spring Summer 2009. Retrieved May 16, 2016, from http://www.marykatrantzou.com/collections/ready -to-wear/spring-summer-2009/runway

Mary Katrantzou. (n.d.b). Runway Looks: Spring Summer 2017. Retrieved May 16, 2016, from http:// www.marykatrantzou.com/collections/ready-to-we ar/spring-summer-2017/runway

McLuhan, M. (2002). 미디어의 이해: 인간의 확장 [Understanding media: The extensions of man]. (S. K. Kim, \& H. W. Lee, Trans.). Seoul: Minumsa. (Original work published 1994)

Mitchell, W. J. (2005). 디지털 이미지론: 포스트포토 그래픽 시대에서 시각적 진실 [The reconfigured eye: Visual truth in the post-photographic era]. (E. J. Kim, Trans.). Seoul: Ivies Publishing.
(Original work published 1992)

Noa Raviv. (n.d.). Collections. Retrieved May 16, 2015, from http://www.noaraviv.com/hard-copycollection/wp1qa8g9oxfnts09jh753gskfvssla

Park, M. A. (2016). The digital fashion in aesthetic perspective of media. Unpublished doctoral dissertation, Konkuk University, Seoul, Korea.

Park, M.-A., \& Ko, H.-Z. (2014). The analysis of the characteristic types of fashion brand application: Concentrating on Korean application cases. Journal of the Korean Society of Costume, 64(1), 136-150. doi:10.7233/jksc.2014.64.1.136

Park, S. H., \& Lee, J. H. (2001). An exploratory research for design of digital fashion product based on the concept of "wearable computer" I . Journal of Fashion Business, 5(3), 111-128.

Planning - Digital design competitiveness; What is Digital Design?. (2003, November 10). [기획-디 지털디자인경쟁력](1); 디지털디자인이란. Economic Times Digital Times, Retrieved September 16, 2015, from http://www.dt.co.kr/contents.html?article no $=2003111002010660614001$

Quinn, B. (2011). Fashion futures. London: Merrell. SDN. (2010, April 22). Digital marketing in fashion. Retrieved November 15, 2011, from http://www. samsungdesign.net/Fashion/Report/Content.asp?an $=1599$

Shin. D. S. (2016, November 21). 3D 프린팅된 명품 브랜드 알렉산더 맥퀸 우산 [3D printed luxury brand Alexander McQueen umbrella]. Retrieved November 24, 2016, from http://ktech21.com/casestudy/3d-printed-umbrella-alexander-mcqueen

Sim, H. R. (2012). 20세기의 매체철학. 아날로그에서 디 지털로 [The media philosophy of the 20th century]. Seoul: Greenbee.

Smart wear. (n.d.). In Doopedia. Retrieved September 16, 2015, from http://www.doopedia.co.kr/doopedia/ master/master.do? method=view\&MAS IDX $=10$ 1013000796062

Ubiquitous computing. (n.d.). In Wikipedia. Retrieved September 16, 2015, from https://ko.wikipedia.org/ 
wiki/ $\%$ EC $\% 9 \mathrm{C} \% \mathrm{~A} 0 \% \mathrm{~EB} \% \mathrm{~B} 9 \% 84 \% \mathrm{EC} \% \mathrm{BF} \% \mathrm{BC}$ $\%$ ED $\% 84 \%$ B0\%EC\%8A\%A4_\%EC\%BB\%B4\%E D\%93\%A8\%ED\%8C\%85

Ubiquitous fashion. (n.d.). In Wikipedia. Retrieved September 16, 2015, from https://ko.wikipedia.org/ wiki/\%EC\%B0\%A9\%EC\%9A\%A9 \%ЕC\%BB\% B4\%ED $\% 93 \%$ A8\%ED $\% 84 \% B 0$

Vogue. (2002, March 9). Viktor \& Rolf: Fall 2002 ready-to-wear. Retrieved August 6, 2015, from http:/www.vogue.com/fashion-shows/fall-2002-re ady-to-wear/viktor-rolf

Vogue. (2006, March 3). Alexander Mcqueen autumn/ winter 2006 ready-to-wear collection. Retrieved August 6, 2015, from http://www.vogue.co.uk/shows/ autumn-winter-2006-ready-to-wear/alexander-mcq ueen/collection

Vogue. (2009a, October 6). Alexander McQueen: Spring
2010 ready-to-wear. Retrieved August 6, 2015, from http://www.vogue.com/fashion-shows/spring2010-ready-to-wear/alexander-mcqueen

Vogue. (2009b, October 6). Alexander McQueen: Spring 2010 ready-to-wear. Retrieved August 6, 2015, from http://www.vogue.com/fashion-shows/spring2010-ready-to-wear/alexander-mcqueen/slideshow /collection\#2

Vogue. (2011, January 26). Jean Paul Gaultier: Spring 2011 couture. Retrieved August 6, 2015, from http:// www.vogue.com/fashion-shows/spring-2011-cout ure/jean-paul-gaultier/slideshow/collection\#43

Vogue. (2015, March 10). Chanel: Fall 2015 couture. Retrieved August 6, 2015, from http://www.vogue. com/fashion-shows/fall-2015-couture/chanel/slide show/collection\#10 